\title{
Turning Points in Development Thinking and Practice
}

\author{
Louis Emmerij*
}

February 2006

\begin{abstract}
Why and when do turning points occur? How are they prepared? What are the choices before us when it comes to economic and social development policies? What is the role of culture in development? Do ideas play a role? What are the interests behind the ideas? The present paper tries to answer these and other questions and compares the advantages and disadvantages of global development theories with regional and local development policies that put more emphasis on the role of culture in economic development.
\end{abstract}

Keywords: growth, development, global and local policies, culture, history, ideas JEL classification: E1, E6, O1

Copyright @ C UNU-WIDER 2006

*United Nations Intellectual History Project (UNIHP), Graduate Center, City University of New York.

This study is a revised version of the paper presented at the 17-18 June 2005 UNU-WIDER anniversary conference, 'WIDER Thinking Ahead: The Future of Development Economics', directed by George Mavrotas and Anthony Shorrocks.

UNU-WIDER gratefully acknowledges the financial contributions to the research programme by the governments of Denmark (Royal Ministry of Foreign Affairs), Finland (Ministry for Foreign Affairs), Norway (Royal Ministry of Foreign Affairs), Sweden (Swedish International Development Cooperation Agency_Sida) and the United Kingdom (Department for International Development). 


\section{Acknowledgements}

I am grateful to my colleagues at the United Nations Intellectual History Project, Richard Jolly and Thomas G. Weiss, for continuous and stimulating discussions.

The World Institute for Development Economics Research (WIDER) was established by the United Nations University (UNU) as its first research and training centre and started work in Helsinki, Finland in 1985. The Institute undertakes applied research and policy analysis on structural changes affecting the developing and transitional economies, provides a forum for the advocacy of policies leading to robust, equitable and environmentally sustainable growth, and promotes capacity strengthening and training in the field of economic and social policy making. Work is carried out by staff researchers and visiting scholars in Helsinki and through networks of collabourating scholars and institutions around the world. www.wider.unu.edu publications@wider.unu.edu

UNU World Institute for Development Economics Research (UNU-WIDER)

Katajanokanlaituri 6 B, 00160 Helsinki, Finland

Camera-ready typescript prepared by Lorraine Telfer-Taivainen at UNU-WIDER

The views expressed in this publication are those of the author(s). Publication does not imply endorsement by the Institute or the United Nations University, nor by the programme/project sponsors, of any of the views expressed. 


\section{A turning point in the balance of thinking and influence}

In this study, I shall first examine why and how the balance of development thinking and practice changed around 1980. This turning point coincided with a change of influence at the level of strategic thinking from the UN to the Bretton Woods Institutions. Second, I shall look into the possibility of future turning points in development thinking and practice. In doing so, I shall describe, first, what could well become (and is already becoming) a new and expanded general concept of development, and second, the very opposite, namely development not as a global but as a regional and local strategy. Thus having examined the future at the global, regional and national levels of development thinking, the study ends with reflections about the interests that lie behind the ideas that help to explain why they get implemented or not, why there are turning points or not.

During the 1940s and 1950s the UN was the place where big ideas about economic and social development policies were initiated. This continued during the 1960s and 1970s with the initiation of the UN Development Decades, the unified approach of UNRISD, and the elaboration of employment and basic needs oriented development strategies by the ILO. It was in this connection that Hans Singer discovered the concept of 'redistribution from growth' during the Kenya High-Level Comprehensive Employment Mission (ILO 1972). During the 1970s the World Bank entered the scene of alternative thinking about development thanks to Hollis Chenery who elaborated and systematized the Singer analysis setting it into a broader statistical framework using data banks and analytical resources from the World Bank. He changed the title in the process from redistribution from growth to redistribution with growth (Chenery et al. 1974).

All this changed at the end of the 1970s with a harsh reversal of economic policies followed hitherto and a move toward neoliberal and neoclassical policies that emphasized privatization and liberalization. This policy reversal was soon followed in all OECD countries and became the conventional wisdom of the West. Contrary to what the innocent bystander might have thought at the time, this 'new' orthodoxy did not come out of the blue. Turning points rarely come out the blue. It had been prepared carefully over time by a core of neoclassical economists. Indeed, the 1970s saw the emergence of two opposing trends in development thinking. One trend consisted in widening the scope of the development strategies pursued by explicitly including social considerations, such as education, health, nutrition, employment, income distribution, basic needs, poverty reduction, environmental considerations, gender, and so on. The other trend was represented by a return to neoclassical thinking. And so, as development thinking during the 1970s became more comprehensive and more poverty and income distribution oriented, the groundwork was laid by the followers of the neoclassical and neoliberal approach that was to become the 'new' paradigm of the 1980s and beyond. For example, the criticism of import substitution became more precise, technical and 
empirical (Little et al. 1970). This early work was followed by other studies that represented an important strengthening of the theoretical framework of the openeconomy model. The same reasoning applies to the monetarist strand of the neoclassical resurgence.

This new paradigm was of course a recycled version of trickle-down economics, with growth given greater weight than income distribution and social objectives. The underlying hypothesis was that policy reforms designed to achieve efficiency and growth would also promote better living standards, especially for the poorest. The social costs of structural adjustment were inconvenient but temporary; in any case they were inevitable in order for countries to return to more rational and viable economic structures. Not only did this 'new' orthodoxy become the economic strategy of the West but, through its adoption by the World Bank and the IMF it became the conventional wisdom of practically the entire globe, whether voluntarily or not. The (important) exception here were the East Asian countries that went under a variety of labels, such as the Asian tigers, the Flying Geese, etc.

The Bretton Woods Institutions adopted the reversal of policies because the Western countries could impose their will in the Board, given the weighted voting system. Once adopted, they (that is, the Bretton Woods institutions and Western countries) could impose it on the rest of the world-also in the light of the international debt crisis. It was a typical case of the power of the purse versus the power of ideas. The purse won mainly, we contend, because of the absence of ideas on the part of the UN and the rest of the world during this period, with the exception, once again, of East Asia.

But, it can be asked, where had all the Nobel laureates gone who had been so instrumental in the early years to shape development thinking both in the UN and in the world at large? In 1980 most of them were still very much alive. Jan Tinbergen, Gunnar Myrdal, W. Arthur Lewis, Richard Stone, James Meade, Amartya Sen and others were still very active. But no consistent counteroffensive was mounted in the early 1980s. True enough, hundreds of British economists1 signed their rejection of Thatcherite economics, but with little effect on practical policy or ideological stance. And so the purse won mainly because the existing ideas of the 1970s were not defended and adapted strongly and carefully enough and no alternative ideas were brought forward in a sufficiently authoritative fashion. We had to wait until the 1990s for this to happenin terms of thinking rather than of practice-when the series of Human Development Reports were launched by Mabub ul Haq and his small team at the United Nations Development Programme (UNDP). ${ }^{2}$

1 Three hundred and sixty-four, to be precise.

2 UNDP (various) Human Development Report. 


\section{The future of development as a global concept}

What is amazing when it comes to development thinking is the dominance of Western ideas. Starting with modernization theory, all the development approaches are 'Western' and are dominated by economists. This remains true even with strategies conceived by thinkers from the South or the East.

The classicists and the other great names in development thinking were all from Europe and secondarily from the United States. Development thinking in the modern era, since 1945, saw a wider cast of characters come to the fore, but it remained a global concept that was not 'deconstructed', to use Escobar's (1995) terminology. The labour-surplus model, the big push, balanced and unbalanced growth, great spurt, and stages of economic growth doctrines were all of European and American extraction. The only person from a developing country-W. Arthur Lewis-did not depart from his neoclassical upbringing.

The same applies to the Marxist school of thought, although to a lesser degree. For instance, Paul Baran saw European colonialism interfering not only with development in the precapitalist colonies but modifying their future development path as well. His analysis points to the asymmetrical power and political relations - rather than god-given 'natural endowments' and free-market-determined 'comparative advantages'-in determining the growth path followed by many underdeveloped countries. Baran (1957) concluded that 'far from serving as an engine of economic expansion, of technological progress, and of social change, the capitalist order in these countries has represented a framework for economic stagnation, for archaic technology and for social backwardness'. Baran and Sweezy (1966) inverted the law of uneven development on a worldscale relative to the formulations of the classical Marxist analysis of imperialism: rather than slowing down the accumulation in the advanced countries, imperialism blocked development in the less developed economies. The internal dynamics of underdeveloped societies came to be seen as fundamentally determined by their insertion into the world capitalist system. Although their analysis was pertinent and interesting, their suggestions for setting up an alternative development approach remained highly tentative and defensive and not really departing from its Western origins.

What is 'Western' about all this is that no account is taken of local thinking in and local theorists of developing countries. A possible exception is Raul Prebisch and the Latin American Structuralist School that emerged in the late 1940s. Here development and underdevelopment are seen as related processes occurring within a single, dynamic economic system. Development is generated in some areas- the Center defined as those countries whose economies were first penetrated by capitalist production techniquesand underdevelopment is generated in others-the periphery. Modern underdevelopment is therefore seen as a result of a process of structural change in the peripheral economies that occurs in conjunction with-is conditioned by, but not caused 
unilaterally by-their relations with the Center (Prebisch 1950). So even here the Western influence is important, as it is in the writings of Cardoso and Faletto (1979), Samir Amin, and others of the dependencia school.

The neoclassical resurgence we have observed since 1980 is of course totally Western bred, but so were the redistribution with growth and the basic needs development strategies of the 1970s. Although the latter did explicitly take into consideration the specific circumstances of the developing countries, they remained embedded in Western concepts and thinking.

The events of the past decades challenge much of the validity of these Western development theories, whether liberal or Marxist, neoclassical or post-Keynesian. They did not anticipate turning points, collapses or failures; neither did they explain them ex post. They do not explain why so many countries do not seem to be able to take off economically or are regressing to previous levels of economic development. They do not explain either the 'ennui' in the apparently successful countries. Examples are the totally unanticipated collapse of communism and the reintegration of Central and Eastern Europe and the former Soviet Union into the capitalist world economy. Nor do they give an explanation of the reappearance of virulent nationalism and ethnic conflicts as well as the rapid growth of militant religious fundamentalism in both Western and non-Western societies. The economic stagnation and decline in African and Latin American countries; the imposition and the lack of success of structural adjustment programs, especially in Africa, the rapid state-led industrialization of the East Asian countries cannot be explained by any rational criteria of the Washington Consensus school. Hence, all of those were on the whole not anticipated by either mainstream or more radical theories of development. In the face of such a failure to foresee major changes it can be maintained that we are witnessing a crisis in development theory even if in practice many stress the average progress achieved.

None of the theories - whether of the modernization, dependency, neoliberal or Marxist variety-seem to be working in the sense that they have all run into trouble, even if initial successes were secured. During the 1980s and 1990s these theories have been supplanted by a hegemonic neoliberal view of development based on 'globalization', 'free markets' that effectively dismiss questions of ethnicity, of culture, and does not try to understand nationalism, fundamentalism and terrorism. It can be maintained that the whole Western model of development, the 'paradigm of modernity', of a secular, industrial nation-state, is now in question and that a coherent and persuasive alternative model is yet to be found.

It would appear obvious that within the global economy enough flexibility must be created to make room for regional and national variations toward development polices, given the specific situation of the region or country in question. For instance, it can hardly be maintained that the Washington Consensus has been a success story in Latin 
America. In 1996, Ajit Singh challenged his Latin American colleagues to say how much more time they needed before being able to say that the Washington Consensus has been a failure. 'Five more years', they answered. ${ }^{3}$ Five years later the picture was as follows: Argentina was in turmoil, President Menem under house arrest, his successor and two more Presidents gone by the wayside; Fujimori was in Japan and his country Peru in trouble; the Mexicans have not waited five years to oust the PRI in power for practically the entire twentieth century, although it is not all clear whether Vicente Fox has been able to find his own way; the Venezuelans sacked the traditional parties who squandered the oil revenues and replaced them by a populist Hugo Chavez; and we could go down the tragic list, from Colombia to Brazil via Ecuador. What lessons can and must be learned from all this?

\section{Toward a new and flexible concept of development: forks in the road}

There are two questions that one must ask when it comes to development theory and practice. The first is whether the approach adopted up until now is comprehensive enough or still too narrowly economistic; the second relates to the problem of homogeneity, i.e. in how far must development policies be adapted and changed according to the culture of a given region or country. In other words, the question before us is whether there is one theory and one practice for the entire world, with a little tinkering at the margins to take account of regional differences, or whether there should be many theories and many practices in order to tailor make development policies according to the culture and habits of countries and regions. So far the former approach has been adopted with mixed results. This approach is now being finessed and broadened and we shall start this section presenting the state of play. The latter approach must be given more thought, as we will show. We are facing a fork in the development road.

\subsection{Broadening development theory and practice}

Amartya Kumar Sen, the 1998 Nobel prize laureate, has given this problem a lot of thought and has come to the conclusion that a universal approach is desirable, as long as development thinking covers a wider surface by bringing on board political, cultural, social and human right issues. One illustration of this belief is the importance he attaches to tolerance and pluralism, of democratic procedures in short: 'To see political tolerance merely as a 'Western liberal' inclination seemed to me a serious mistake'.4 Sen has always adopted a broad approach to development, including work on economic inequality, poverty, employment, technology, investigating the principles and implications of liberty and rights, assessing gender inequality, etc. In other words, his

3 Singh (1997: 48-61).

4 'Autobiography of Amartya Kumar Sen', www.nobel.se/economics/laureates/1998/sen-autobio.html, p. 4. 
interest gradually shifted from the pure theory of social choice to more 'practical' problems (Sen 1982, 1984).

Subsequently, Sen (1985) started to explore an approach that sees individual advantage not merely as opulence or utility, but primarily in terms of the lives people manage to live and the freedom they have to choose the kind of life they have reason to value. The basic idea here is to pay attention to the actual 'capabilities' that people end up having. He elaborated his work on poverty by coming up with a universal definition, not of course in terms of purchasing power but of capabilities and functionings. The poor are poor because their set of capabilities is small, not because of what they do not have, but because of what they cannot do. This measure is universal because it entails identifying a set of capabilities, something like basic needs. A minimum list would include being able to lead a healthy and productive life, to communicate and participate in your community, to move about freely, and to have a family with a partner of your choice.

Thus, Sen has elaborated a distinct agenda. Utility and income have been displaced from their primary positions in orthodox economics. Wellbeing is captured by things people can do rather than things people have. If their set of capabilities grows larger, people can do more of the things they would like to do. And so we arrive at a new and dynamic definition of freedom; choice over a larger set of capabilities (Desai 2000). Sen's (1999) emphasis on freedom of choice led him naturally to attach prime importance to democracy as a preferred political system: 'A country does not have to be deemed fit for democracy; rather, it has to become fit through democracy.

But what exactly is democracy? Sen asserts that we must not identify democracy with majority rule. Democracy does, of course, include voting and respect for election results, but it also requires the protection of liberties and freedoms, respect for legal entitlements, and the guaranteeing of free discussion and uncensored distribution of news and fair comment. 'Even the idea of 'needs', including the understanding of 'economic needs', requires public discussion and exchange of information, views, and analysis (Sen 1999: 10).

Thus, Amartya Sen does not quite trust unadulterated market economics, is in favour of democratic decision making, and calls for social support in development. He has been arguing in favour of softer, gentler and more humane economics and economic policies. When he was awarded the Nobel Prize in 1998, he was credited by the Royal Swedish Academy with 'having restored an ethical dimension to economics'. He points out that in the classical writings on development it was always assumed that economic development was a benign process, in the interest of the people. The view that one must ignore any kind of social sympathies for the underdog, and that you cannot have democracy, did not become the dominant thought until the beginning of modern 
development economics, say as of the 1950s.5 Sen elabourates on the notion of development viewed as a 'fierce' as opposed to seeing it as a 'friendly' process. The former asks for a 'needed sacrifice' in order to achieve a better future. This approach, with its emphasis on capital accumulation, is not wrong, but suffers from several handicaps mostly relating to the comparative neglect of the wellbeing and quality of life in the present and near future. Sen (1997: 537) concludes:

Those who see in this a model to follow have continued to argue for giving priority to business ... interests so that the productive power of the nation can be radically expanded, and they warn against the spoiling of long-run benefits by the premature operation of sympathy; they are terrified of the harm that may result from the influence of 'bleeding hearts'. The 'friendly' approach, by contrast, sees development as a process where people help each other and themselves with an emphasis on human skills and human capital, and on the role of human qualities in promoting and sustaining economic growth. Ultimately, the focus is on the expansion of human freedom to live the kind of lives people have reason to value. And, thus, the role of economic growth in expanding these opportunities has to be integrated into that more foundational understanding of the process of development.

And so we have been moving toward a global, a universal concept of development in which physical and human capital accumulation remain important ingredients, but where social objectives, freedom, democracy, ethnicity, human rights are becoming at least as crucial. It took time to realize that education is not just a consumption good that can be afforded as of a certain level of development, but that it is also an investment in human capital that is a prerequisite to attain that level of development. In the same way, we must now get used to the idea that social and ethnic inequalities, absence of freedom and democracy are as much reasons for lack of development than absence of investments. The concept of development not only becomes much more comprehensive and all embracing, but the causative links and relationships are being reversed. This line of thought also underlies the concept of human development, initiated by ul Haq (with the active assistance of Sen) in the Human Development Reports mentioned earlier.

Obviously, it can be argued that the 'Sen approach' to development must be more formally formulated in terms of an economic and social development model. Physical and human capital investments, sector allocation, human rights, freedom, etc must be integrated in a consistent whole in order to move away from words and toward a formal model.

5 'Humane Development - An Interview with Amartya Sen, the Nobel Prize-winning Economist and Author of Development as Freedom', www/theatlantic.com/unbound/interviews/ba991215.htm, pp. 2-3. 


\subsection{Breaking down development nationally, locally and culturally}

There is a growing awareness of the importance of culture in the development process and of the cultural assumptions inherent in development theory and practice. The preceding section is based on the assumption that by broadening the concept of development the range of development models becomes progressively narrower. But the question that is being asked today is whether development models are determined culturally by each region, or by the culture of one region, namely the West. 6 Culture will be defined here in a broad sense, as a way of life and living together. This relates to values people hold, to tolerance with respect to others (race, gender, foreigners), to outward versus inward orientations and inclinations, etc.

More cultural freedom leaves us free to meet one of the most basic needs, 'the need to define our own basic needs' (UNESCO 1995: 15). But defining one's own basic needs is one thing, the way to attain them, through which social and economic policies, for instance, is another. We must be careful to maintain a balance between universalism and localism and avoid moving from one extreme to another. The thesis of those who are in favour of more variety in development policies linked to local cultures, institutions and habits, goes somewhere along the following lines:

(i) Western culture has held an iron grip on development thinking and practice;

(ii) this influence has tended to increase further during the past twenty years; but

(iii) there do exist alternative development models based on a different cultural and institutional historical background; and

(iv) these alternatives are likely to multiply in the era of globalization that may, therefore, paradoxically witness more diversity rather than uniformity.

Examples of such variations in development policies can be given. The Japanese and other East Asian authorities have always maintained that globalization does not imply that a universal model or uniform set of rules-as for instance implied in the Washington Consensus, but also in Sen's much broader concept-spread to all parts of the world. According to one Japanese authority (a hard nosed top official of the Ministry of Finance who went under the nickname Mr Yen) 'we have to recognize that what can be called localization, or an identification with local cultural values, is proceeding along with globalization' (Sakakibara 1997). As was implied earlier most neoclassical economists tend to apply their 'universal' model unilaterally to all countries, neglecting the historical, institutional and cultural backgrounds of the countries in question. But there are doubters who recognize the plurality of economic systems or cultures and emphasize the interaction among them. For them the key concept is not universality, but diversity and interaction.

6 See for instance Escobar (1995). 
For instance, it has been argued by many economists that deregulation must be implemented as intensively as possible, simultaneously and quickly on many fronts. But such an approach implicitly assumes that Anglo-American institutions are already in place or can be quickly established by enlightened reformers with the help of consultants and international organizations. This neglect of the validity of different cultures and evolutionary processes of history has often led to confusion and the collapse of the existing order rather than to reform. How can proper macroeconomic policies be conducted if the necessary infrastructure such as a central banking system and an effectively governed enterprise system do not exist? Forcing a uniform model on diverse country and cultural situations may endanger the economic future of these countries, as well as that of the world at large.

The need for a differentiated approach has long been obvious, in view of the remarkable success of the East Asian development experience. This need is also felt because of the disquieting fact that in most countries that have adopted the current economic orthodoxy (read Washington Consensus) during the past 20 years or so, the distribution of income has worsened, poverty has tended to increase, and employment trends have been very uneven. The causal linkages have not yet been well understood, but the association between the adoption of a specific uniform model and the accentuation of problems of inequality and poverty is a cause for serious concern. If one of the priorities is 'to bring the millions of dispossessed and disadvantaged in from the margins of society and cultural policy in from the margins of governance' (Council of Europe 1996: 9), then bringing these two together by adapting the development models according to the needs, institutions, history and culture of different societies is an absolute must. The margins of manoeuvre may not be huge, but wider than one might suspect at first sight. That much has become clear from the East Asian development experience. These margins refer to institutions, consumption habits, land rights, property rights in general, access to markets, distribution systems, economic democracy, etc. The growing internationalization and globalization may provoke diversity at least as much as imposing uniformity.

Participation and empowerment are, obviously, closely related to both cultural and economic rights and equality. Participation, a human right, is one of the key objects of cultural and economic policy, because it opens up both the economy and culture to as many people as possible. It is often forgotten that East Asian countries could only grow at such stupendous rates of 8 to 9 per cent a year over such a long time, because there was full employment, that is, everybody participated actively in the economy. In other words, there was growth from below. One cannot expect countries to grow much beyond 3 to 4 per cent until the bottom half of the population is participating and contributing. 'The issue is not so much that of growth with distribution; growth with distribution can be achieved by a few cooks preparing a pie and distributing the pieces to a larger group through transfers. It is instead a matter of the poor becoming cooks 
too, and of more cooks preparing a bigger pie' (Birdsall: 1997: 394-99). For the 'poor' one can and must read immigrants, women, unemployed, certain ethnic groups, etc.

East Asia can be seen as a mild case of economic differentiation from the mainstream. It was less based on theory than on actual practice. There is, however, a school of thought that wants to go further. This school is best illustrated by the 'decontructionist' approach of Escobar (1995). What this school is pleading for is differentiated development policies based on the cultural, institutional and historical characteristics of a given region as determined by the participation and empowerment of the people. It is a bottom-up approach pushed to its extreme. However, if an extreme approach is discarded, what remains is an important policy alternative, namely the desirability to include local variations on the national, regional and global development theme. The 'realistic' approach here takes as a starting point the alleged fact that development policies are to a very large extent top-down, ethnocentric and technocratic that treat people and cultures as abstract concepts. They are composed of a series of technical interventions that are supposed to be universally applicable. The alternative is to be much more sensitive to local and social and cultural practice that is producing local models of economic activity. In other words, 'the remaking of development must thus start by examining local constructions, to the extent that they are the life and history of a people, that is, the conditions of and for change' (Escobar 1995).

According to this school of thought, development theory and practice has not paid sufficient attention, if at all, to the cultural dynamics of incorporating local thinking and practice into the global orthodoxy of economic thought. Nor has it attempted to make visible the local constructions that exist side by side with the might of global forces. There is, therefore, no question of proposing grand alternatives here; alternatives that can be applied to all places and all situations. In a sense, the proponents of this version of deconstruction go further than that by introducing many local variations on the general theme (any general theme) that in turn will effect the global orthodoxy.

We have reviewed here examples of development approaches that attempt to broaden the scope in order to make them more comprehensive on the one hand, and of allowing local traditions and practice to play an important role on the other. Both approaches have the same rationale, namely to make the development policies more realistic and hence to produce better results for all individuals on this earth. However, both would imply a turning point in development policies at some time in the future. And once again, just like the turning point around 1980, it will not have come out of the blue.

\section{The interests behind the ideas}

'An idea whose time has come', as the saying goes. Why does the time for certain ideas come, when it comes? What are the political and other interests involved? Can really important ideas that change institutions and structures only be adopted after a disaster? 
Why are certain periods in history pervaded by optimism and action and others by pessimism and passivity? What explains these cycles of optimism and pessimism, of action and passivity, of moving from one extreme to another?

On a personal note, I have been very much influenced in my answer to such questions by an event that happened when I was a young man in The Netherlands. On 1 February 1953 the dikes broke and a flood resulted in which more than 2,000 people drowned. During the debate that followed it became clear that warning signals had been given frequently in the past to the effect that such a disaster could happen if and when an exceptional combination of events occurred (full moon, northwestern gales of a certain force, etc.). The probability for such a constellation of factors to happen was, however, small. And so successive Dutch governments said 'Apres nous le deluge', and nothing was done. It was only after the deluge actually happened that a long-term plan was elaborated (the so-called Delta Plan) to cut off all big rivers from the sea at very considerable expense. The impressive result of dikes, bridges and other works of art can be admired by anybody driving from Antwerp to Rotterdam today.

The long-term plan and the considerable expense were only decided upon after the disaster. In the same way it took the disasters of the Great Depression and the Second World War to adopt new economic policies and a new international financial and political architecture by introducing and embracing Keynesian economics, the Bretton Woods institutions, the UN, and the Marshall Plan. So one thing is quite clear. Important ideas and exceptional people get more of a chance in exceptional circumstances and when disasters are on us. This is sad but true. Cassandras are never listened to, as the Dutch experts learned at their and the population's expense, and as we can also deduce from the environmental and Kyoto saga. 7

Can one find exceptions to this 'rule' where disasters are headed of before they strike? To a certain extent, yes. One could point to the advances in road and car safety, although the number of annual deaths on the roads continues to amount to an infinitely bigger disaster each year than the number of deaths during the 1953 flood in The Netherlands. The immunization programme as launched by UNICEF during the 1980s would come close to a real exception to the rule, although once again the number of children that died each year before the programme was dreadful. The green revolution and the new seeds are probably the clearest exception to the rule, but even here hunger and its victims has already struck many times. An intelligent policy approach to global warming would be the real exception, but we are not yet there. 8

What makes the difference when it comes to the multitude of ideas at the second and third level of importance where millions of lives may be at stake but that do not

7 See also Jenkins (2001).

8 See, for example, Lomborg (2001: chapter 24). 
revolutionize the existing political and institutional structure? What makes that the time has come for them or not? There are several reasons that can be mentioned here. First, there is the question of leadership. Strong, enlightened and visionary leadership can make all the difference in order to bring an idea to the attention of national policy makers worldwide. Courage and standing for one's convictions go with this kind of leadership.

A second reason is chance. It is like scientific research where one is looking for $\mathrm{x}$ and stumbles on y. John Maynard Keynes started out as a neoclassical economist and while writing the General Theory became 'Keynes'. Raul Prebisch was a conventional central banker and while examining the data that Hans Singer had sent to him plus those he had collected himself became an unconventional economist and an advocate in favour of import substitution and center-periphery analysis. It is the combination of leadership and chance that can be very powerful. A case in point is Jim Grant meeting Jon Eliot Rohde who convinced him that more than half of all the deaths and disease among the children of the developing world was unnecessary, 'because it was now relatively easy and cheaply preventable' (Jolly 2001: 21). Other examples, like the eradication of smallpox, could be found.

A third reason is participatory decision making. As already Max Weber remarked 'interaction creates ideas, imposing kills them' ${ }^{9}$ In the social sciences, ideas rarely come to the isolated individual shivering in the cold of his or her room in the attic. They rather come through the interaction of many individuals and groups in the warm rice fields of Asia, for instance. The Green Revolution is an illustration of this thesis in that it came about through a mix of high-powered research and putting one's ear to the ground. Listening to grass root movements, to neighborhood groups, etc., may well result in getting or sharpening ideas. It requires humility on the part of the professional to listen to those local workers, from another culture and with another mindset. It is at this point that we join what was said in Section 3 about identity and global development ideas or, as we called it, local variations on a global theme.

But let us not make a secret about it, in the end money and power count a great deal when it comes to which ideas come to the fore and which are implemented. Money, therefore, is the fourth reason. A telling illustration here is the story of the policies that were to guide the transition countries in Central and East Europe and the former Soviet Union to transform them into capitalist societies. The battle of ideas was between the 'big bang' approach and a more gradual, friendlier way of realizing this difficult transition. The idea that finally won was not necessarily the best, but rather the one with money and political clout to back it up. In the end it is obvious that an idea without the

9 Max Weber, Essays in Sociology, in which he also stated that interests (material and ideal), not ideas, dominate directly the actions of men. 
backing of money and other forms of influence will never see the light of day. Or rather it may see the light of day but it will remain sidelined.

The interests behind the ideas are a combination of the ambition of leaders, of influence, of local grass root movements, and of money with chance thrown in for good measure. Once again, inspired leadership is of the essence and so is humility to learn from the people on the ground. There are many ideas around that can result in better development policies and hence improve the living conditions of millions of people. Identifying them takes an open mind, a lot of curiosity and the will and leadership to bring them to the attention of the world. Baudrel (1985: 542) in one of his masterpieces, said it best:

Sometimes an invention appears in isolation, brilliant but useless, the sterile fruit of some fertile brain; no more is heard of it. Sometimes there is takeoff of a kind ... there is a burst of progress, the motor seems on the point of starting, and then the whole thing comes to a halt ... A burst of progress followed by a collapse. Imperfect repetitions of each other though they may be, they are repetitions all the same and obvious comparisons practically suggest themselves.

\section{References}

Baran, P. (1957). The Political Economy of Growth, Monthly Review Press: New York.

Baran, P., and P. Sweezy (1966). Monopoly Capital, Monthly Review Press: New York.

Birdsall, N. (1997). 'Lessons from Japan', in L. Emmerij (ed.) Economic and Social Development into the XXI Century, Johns Hopkins University Press: Baltimore.

Braudel, F. (1985). Civilization and Capitalism: $15^{\text {th }}-18^{\text {th }}$ Century: The Perspective of the World, Fontana Paperbacks: London.

Cardoso, F.H., and E. Faletto (1979). Dependency and Development in Latin America, University of California Press: Berkeley CA.

Chenery, H., M.S. Ahluwalia, C.L.G. Bell, J.H. Duloy, and R. Jolly (1974). Redistribution with Growth: Policies to Improve Income Distribution in Developing Countries in the Context of Economic Growth, Oxford University Press: Oxford.

Council of Europe (1996). In from the Margins, Council of Europe: Strasbourg.

Desai, M. (2000). 'Portrait: Amartya Sen', Prospect July: 49.

ILO (1972). Employment, Incomes, and Equity: A Strategy for Increasing Productive Employment in Kenya, International Labour Office: Geneva.

Jenkins, R. (2001). Churchill: a Biography, Farrar, Strauss \& Giroux: New York.

Jolly, R. (ed.) (2001). Jim Grant: UNICEF Visionary, UNICEF: Florence. 
Little, I.M.D., T. Scitovsky, and M.F.G. Scott (1970). Industry and Trade in Some Developing Countries, Oxford University Press: Oxford.

Lomborg, B. (2001). The Skeptical Environmentalist: Measuring the Real State of the World, Cambridge University Press: Cambridge.

Prebisch, R. (1950). The Economic Development of Latin America and its Principal Problems, United Nations: New York.

Sakakibara, E. (1997). 'Globalization amid Diversity’, in L. Emmerij (ed.) Economic and Social Development into the XXI Century, Johns Hopkins University Press: Baltimore.

Sen, A.K. (1982). Choice, Welfare and Measurement, Harvard University Press: Cambridge MA.

Sen, A.K. (1984). Resources, Values and Development, Harvard University Press: Cambridge MA.

Sen, A.K. (1985). Commodities and Capabilities, Oxford University Press: Oxford.

Sen A.K. (1997). 'Development Thinking at the Beginning of the XXI Century', in L. Emmerij (ed.) Economic and Social Development into the XXI Century, Johns Hopkins University Press: Baltimore.

Sen, A.K. (1999). 'Democracy as a Universal Value', Journal of Democracy 10(3): 317.

Singh, A. (1997) 'Catching up with the West: a Perspective on Asian Economic Development and Lessons for Latin America', in L. Emmerij (ed.) Economic and Social Development into the XXI Century, Johns Hopkins University Press: Baltimore.

UNDP (various). Human Development Report Oxford University Press: New York.

UNESCO (1995). Our Creative Diversity, UNESCO: Paris. 